\title{
Evaluating Efficiency Improvement of Deep-Cut Curb Inlets for Road-Bioretention Stripes
}

\author{
Xiaoning Li ${ }^{1} \oplus$, Chuanhai Wang ${ }^{1}$, Gang Chen ${ }^{1} \oplus$, Qiang Wang ${ }^{2} \oplus$, Zunle $\mathrm{Hu}^{3}$, Jinning $\mathrm{Wu}^{3}$, \\ Shan Wang ${ }^{3}$ and Xing Fang ${ }^{4, *}$ (D) \\ 1 College of Hydrology and Water Resources, Hohai University, Nanjing 210098, China; \\ xz10938@hhu.edu.cn (X.L.); chwang@hhu.edu.cn (C.W.); gangchen@hhu.edu.cn (G.C.) \\ 2 Changzhou Urban Flood Control Management Office, Changzhou 213000, China; wq190598159@163.com \\ 3 Changzhou Branch of Jiangsu Hydrology and Water Resources Survey Bureau, Changzhou 213022, China; \\ zunlehu@163.com (Z.H.); wjnxx@163.com (J.W.); wangshan333@126.com (S.W.) \\ 4 Department of Civil and Environmental Engineering, Auburn University, Auburn, AL 36849-5337, USA \\ * Correspondence: xing.fang@auburn.edu; Tel.: +1-334-844-8778
}

Received: 28 October 2020; Accepted: 28 November 2020; Published: 30 November 2020

check for updates

\begin{abstract}
Making a deep cut on the curb inlet has been used in some sponge-city (SPC) projects for road-bioretention stripes to manage stormwater runoff since they were easily implemented in the field. The efficiencies of the deep-cut curb inlets in those projects were unknown for lacking equation to evaluate their efficiencies. Two kinds of retrofit scenarios are commonly used: (1) The curb-cut cases when the deep cut is made only over the width of the curb inlet; (2) the road-curb cut cases when both the curb inlet and a small part of the road surface have a deep cut. An updated two-dimensional flow simulation program, FullSWOF-ZG, was used to determine two important parameters in road curb inlet design: The $100 \%$ interception curb inlet lengths $\left(L_{T}\right)$ and the curb inlet efficiencies $\left(E_{c i}\right)$. Eight-hundred retrofit modeling cases were compared with the no-cut cases to quantify the efficiency improvement of the deep-cut curb inlets. The simulation results show both $L_{T}$ and $E_{c i}$ of the curb-cut cases do not improve much. This case study with limited combinations of longitudinal and cross slopes and inlet lengths demonstrated that $E_{c i}$ of the road-curb cut cases improves to a large extent so that they can be used in the SPC projects and other urban drainage projects to reduce the flooding potentials. A general equation used to design and evaluate the road-curb cut inlets can be developed based on more simulation cases with a wide range of input parameters in a future study.
\end{abstract}

Keywords: stormwater management; deep-cut curb inlet; two-dimensional overland flow; curb inlet efficiency; road-bioretention

\section{Introduction}

Curb inlets are important drainage components for urban stormwater management to traditionally intercept the surface runoff into underground stormwater pipelines or to capture runoff into road-bioretention stripes for infiltration and water quality improvement in many recent designs (Figure 1). The hydraulic performance of undepressed curb inlets (Figure 1b) for roadway drainage has been studied for more than 60 years, which was reviewed and summarized by Izzard [1], Li [2], and systematically documented in the Hydraulic Engineering Circular No. 22 (HEC-22) by Brown et al. [3]. In HEC-22, there are two steps to design curb inlet: (1) Calculate the 100\% interception curb inlet length $\left(L_{T}\right.$, the curb-opening length when all upstream inflow is intercepted by the curb inlet) based on road longitudinal slope $\left(S_{0}\right)$, cross slope $\left(S_{x}\right)$, and roughness; $(2)$ calculate the curb inlet efficiency $\left(E_{c i}\right.$, the curb inlet intercepted flow divide by the total inflow from the upstream boundary) based on curb inlet length $\left(L_{c i}\right)$ and $L_{T}$. 


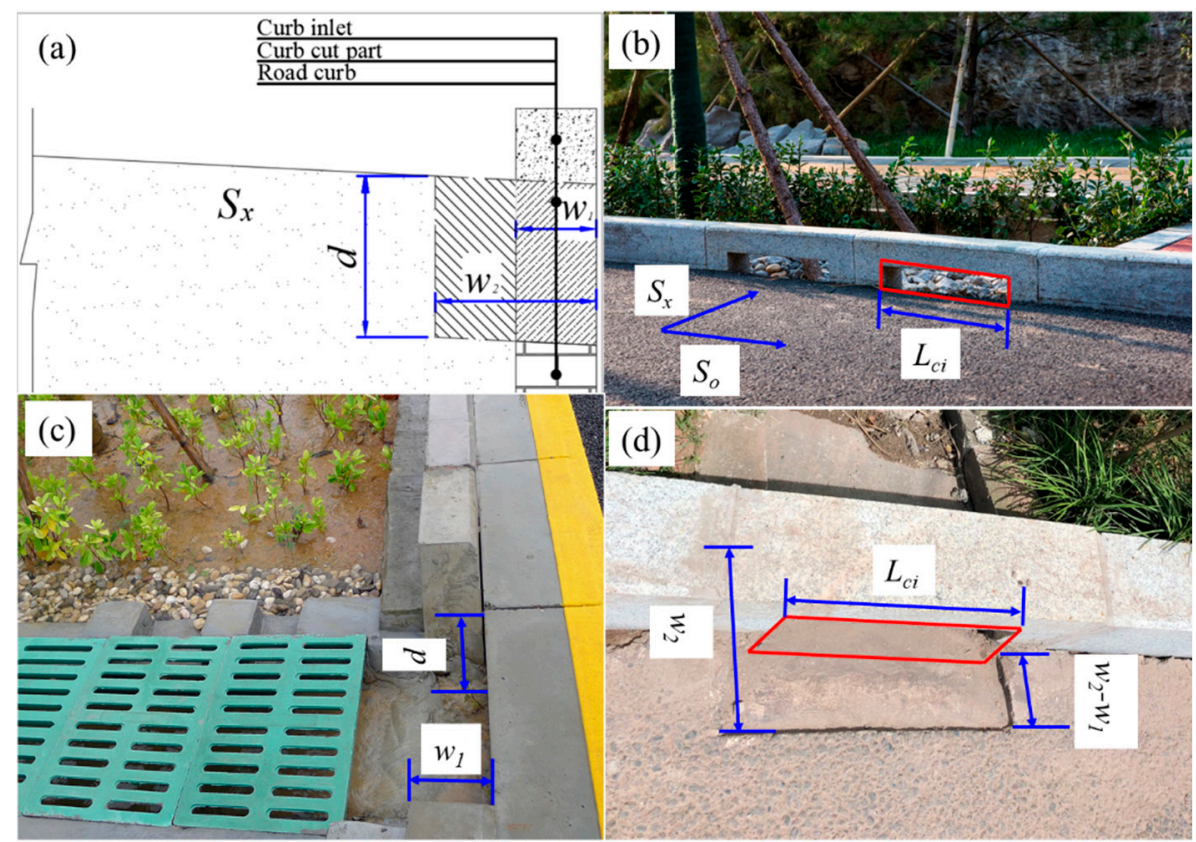

Figure 1. (a) Cross-section view and dimensions of the curb inlet (b) undepressed (no-cut) curb inlet (c) "curb-cut" curb inlet (d) "road-curb cut" curb inlet photos, where $L_{c i}$ is the curb length, $S_{0}$ and $S_{x}$ are the longitudinal and cross slopes of the road surface, $d, w_{1}$, and $w_{2}$ are the deep-cut depth and widths.

The undepressed curb inlets have one cross slope for the road surface including the gutter and the curb inlet (Figure 1b). The deep-cut curb inlets (Figure 1c,d) by cutting/deepening curb inlet, were used in some of the retrofit sponge city (SPC) projects for that they were easily implemented based on engineer's or designer's field experience. The implementation of the deep cuts was based on some field observations that the undepressed curb inlets could not effectively intercept the runoff from the road surface into the bioretention strip along roads. To improve the interception efficiency, the undepressed curb inlet was retrofitted by simply cutting the curb inlet deeper to create a local depression, for example, making the curb inlet opening area to be $0.10-0.15 \mathrm{~m}$ lower than the original surface (Figure 1c). This is the first type of deep-cut curb inlets, called "curb-cut inlet" in this study (or when $w_{2}=w_{1}$ in Figure 1a). The second type of deep-cut curb inlets is called "road-curb cut inlet" when an undepressed curb inlet was retrofitted by cutting curb inlet and a small part of the road deeper to create a wider local depression (Figure 1d) when $w_{2}>w_{1}$ in Figure 1a. The efficiencies of both types of deep-cut curb inlets in those projects were unknown because there is no standard equation that can be used to calculate their efficiencies.

To determine inlet efficiency and performance, the reduced-scale physical models were used in some studies and based on Froude number scaling, for example, a 3:4 scale model for Hammonds and Holley's study [4], 1:4 for Uyumaz's research [5], and 1:3 for Guo and Mackenzie's tests [6]. Only Schalla et al. [7] conducted full-scale experiments for the curb inlet. Fang et al. [8] used a three-dimensional computational fluid dynamics (CFD) software, Flow-3D, to develop the numerical models simulating unsteady, free-surface, shallow flow through local depressed curb-opening inlets. They demonstrated that an advanced CFD model could be used as a virtual laboratory to evaluate the performance of curb inlets with different geometry and inflow conditions. In this study, full-scale numerical models were built up and simulated with two-dimensional (2D) FullSWOF-ZG (Li et al. 2019), which fully (Full) solves shallow water (SW) equations for overland flow (OF) and includes submodules modeling infiltration by zones $(Z)$ and flow interception by grate-inlet $(G)$, to study the hydraulic performance of curb inlets.

Compared to undepressed curb inlets, the deep-cut curb inlets at the gutter may have a larger interception capacity for the road-bioretention strips [3]. However, the performance of the curb inlets 
with two types of deep cuts (Figure 1c,d) was still not quantified in previous studies. This study aims to help more engineers and designers to perform the curb inlet hydraulic design rather than only design it from a landscape perspective for road-bioretention strips since we can quantify the performance improvement of the deep-cut inlets based on two-dimensional overland flow simulation results. Using the FullSWOF-ZG program, it is possible to quantify efficiencies of different types of curb inlets with hundreds of model parameter combinations. These results provide useful information on the design and retrofit of curb inlets for the road-bioretention strips and to determine whether and how the deep-cut should be implemented.

\section{Materials and Methods}

\subsection{Overland flow Simulation Model and Verification Cases}

The FullSWOF-ZG was used in this study to simulate the two-dimensional overland flow on the road surface and developed from FullSWOF_2D (version 1.07, Lab. J. A. Dieudonné \& EPU Nice Sophia, Nice, France) [9]. The submodules for determining infiltration by zones (pervious and impervious zones in the simulation domain) and grate-inlet drainage from the 2D surface to the 1D pipe were added to the open-source FullSWOF_2D program. FullSWOF_2D fully solves the shallow-water equations (SWEs) for overland flow in two dimensions, which is programmed using $\mathrm{C}++$ to describe the rainfall-runoff and flow distribution progress on the surface in 2D domains [10]. Therefore, the FullSWOF-ZG program can simulate impervious and pervious surfaces (different infiltration parameters or capabilities in different zones) simultaneously under rainfall events. The 2D-1D grate-inlet drainage submodule enables the program to simulate the $2 \mathrm{D}$ overland runoff flowing into a grate inlet then to a $1 \mathrm{D}$ underground drainage pipe using the weir equation [11]. The model was tested and validated in the previous studies [12-14] by comparing it with the collected experimental data.

The two-dimensional SWEs for the FullSWOF_2D program, including the continuity equation and two momentum equations in the $x$ - and $y$-directions, is stated as the following equations for each computational cell (center coordinates $x$ and $y$ ):

$$
\begin{gathered}
\frac{\partial h}{\partial t}+\frac{\partial h u}{\partial x}+\frac{\partial h v}{\partial y}=R_{i}(x, y)-f(x, y) \\
\frac{\partial h u}{\partial t}+\frac{\partial}{\partial x}\left(h u^{2}+\frac{g h^{2}}{2}\right)+\frac{\partial}{\partial y}(h u v)=-g h\left(\frac{\partial z}{\partial x}+S_{f x}\right) \\
\frac{\partial h v}{\partial t}+\frac{\partial}{\partial x}(h u v)+\frac{\partial}{\partial y}\left(h v^{2}+\frac{g h^{2}}{2}\right)=-g h\left(\frac{\partial z}{\partial y}+S_{f y}\right)
\end{gathered}
$$

where $R_{i}(x, y)(\mathrm{m} / \mathrm{s})$ is the cell's rainfall intensity; $f(x, y)(\mathrm{m} / \mathrm{s})$ is the cell's infiltration rate; $h(\mathrm{~m})$ is the cell's water depth; $z(\mathrm{~m})$ is the cell topography elevation as a function of the cell location or $x$ - and $y$ - coordinates; $u(\mathrm{~m} / \mathrm{s})$ and $v(\mathrm{~m} / \mathrm{s})$ are the cell's depth-averaged velocities in the $x$ - and $y$ - directions, respectively; $S_{f x}$ and $S_{f y}$ are the cell's friction slopes in the $x$ - and $y$ - directions, respectively; $g\left(\mathrm{~m} / \mathrm{s}^{2}\right)$ is the gravity acceleration; and $t(\mathrm{~s})$ is time.

The FullSWOF_2D program fully solves SWEs on a structured mesh (square cells) in two dimensions using the finite volume method that ensures mass conservation compared to the finite difference method [15]. A well-balanced numerical scheme was adopted to guarantee the positivity of water depth and the preservation of steady states for specific hydrological features such as during wet-dry transitions and tiny water depths $[9,16]$. A modified bi-layer (crust- and soil-layer) Green-Ampt infiltration model [17] to calculate $f(x, y)$ for Equation (1) was added in the FullSWOF_2D [15], which enables the program to simulate the overland flow on impervious and pervious surfaces simultaneously.

FullSWOF_2D was tested against the data from undepressed curb inlet cases in Spaliviero's [18] study; local depressed curb inlet cases conducted by Hammonds and Holley [4]; and overland flow on 
previous surface cases observed by Esteves et al. [17]. The differences of simulated and observed curb inlet interception efficiencies $(\Delta E)$ ranged from $-3.7 \%$ to $4.4 \%$ with an average \pm standard deviation of $0.8 \% \pm 2.6 \%$ for undepressed curb inlet cases [19]. The percent differences of simulated and observed intercepted efficiencies (PDE) ranged from $-4.8 \%$ to $18.7 \%$ with an average \pm standard deviation of $3.7 \% \pm 8.3 \%$. The differences, $\Delta E$ ranged from $-3.2 \%$ to $13.2 \%$, with an average \pm standard deviation of $3.5 \pm 3.5 \%$ for local depressed curb inlet cases. The percent differences, PDE of the simulated and observed intercepted efficiencies ranged from $-6.0 \%$ to $28.7 \%$, with an average \pm standard deviation of $6.6 \pm 7.3 \%$ [12]. In a previous study by Fang et al. [8], the differences $\Delta E$ ranged from $-7.0 \%$ to $17.6 \%$, with an average \pm standard deviation of $1.0 \pm 4.87 \%$ in their 3D FLOW-3D simulations for local depressed curb inlet. The percent differences, PDE for Fang's study ranged from $-19.7 \%$ to $6.1 \%$, with an average \pm standard deviation of $-0.8 \pm 5.7 \%$. These $2 \mathrm{D}$ overland flow simulation cases using the FullSWOF-ZG program were almost as good as the FLOW-3D cases used in the previous study when trying to simulate the interception efficiency of the local depressed curb inlet cases under different situations, but the simulation time was much shorter for running 2D FullSWOF-ZG. The Nash-Sutcliffe Efficiency (NSE) coefficient [20] of FullSWOF-ZG and Esteves's study ranged from 0.64 to 0.95 (average \pm standard deviation as $0.75 \pm 0.11$ ) and from 0.46 to $0.93(0.79 \pm 0.15)$ for overland flow on pervious surfaces simulation, respectively [14]. The simulated results for undepressed curb inlet, local depressed curb inlet, and overland flow on previous surface cases were matched well with the observed data, which proves that the FullSWOD-ZG program can not only simulate overland flow on pervious and impervious surfaces accurately, but also predict the curb inlet efficiency very precisely.

\subsection{Modeling Cases for the Deep-Cut Curb Inlets}

Two types of retrofitted curb inlets were simulated in this study: (1) Curb-cut inlets when the deep cut is made only over the width of the curb inlet (Figures $1 \mathrm{~b}$ and 2a,b); (2) road-curb cut inlets when both the curb inlet and a small part of road surface have a deep cut (Figures $1 \mathrm{c}$ and $2 \mathrm{c}, \mathrm{d}$ ). The curb width or thickness for all modeling cases was set at $0.10 \mathrm{~m}(10 \mathrm{~cm})$ along the cross-slope direction. Typically, the deep-cut depth $d$ (Figure 1c) could be about 0.05-0.20 m. For the curb-cut inlets, 200 modeling cases with one longitude slope $S_{0}, 10$ cross slopes $S_{x}, 10$ upstream inflows ( $Q_{i n}$, Figure 2$)$ were used in this study to determine the $100 \%$ interception curb inlet lengths, $L_{T}$ with $d=0.10 \mathrm{~m}$ or $0.15 \mathrm{~m}$ when the curb or cut width $w_{1}=0.10 \mathrm{~m}$. Another 200 modeling cases with the same longitude slope and 10 cross slopes plus 10 curb inlet lengths ( $L_{c i}$, Figure $1 \mathrm{~d}$ ) were used to determine the curb inlet efficiencies $E_{c i}$ with $d=0.10 \mathrm{~m}$ or $0.15 \mathrm{~m}$. For the road-curb cut inlets, the above-mentioned 400 modeling cases were used to determine either $L_{T}$ or $E_{c i}$ with a cut width on the road surface $\left(w_{2}-w_{1}\right)$ equal to $0.05 \mathrm{~m}$ or $0.10 \mathrm{~m}$ (Figure 1c) when $d$ is set to $0.1 \mathrm{~m}$. Therefore, a total of 800 modeling cases for the deep-cut curb inlets were designed and modeled using the FullSWOF-ZG program. These cases were compared with the undepressed curb inlet cases to quantify the efficiency improvement for two types of deep-cut curb inlets (Figure 1). 

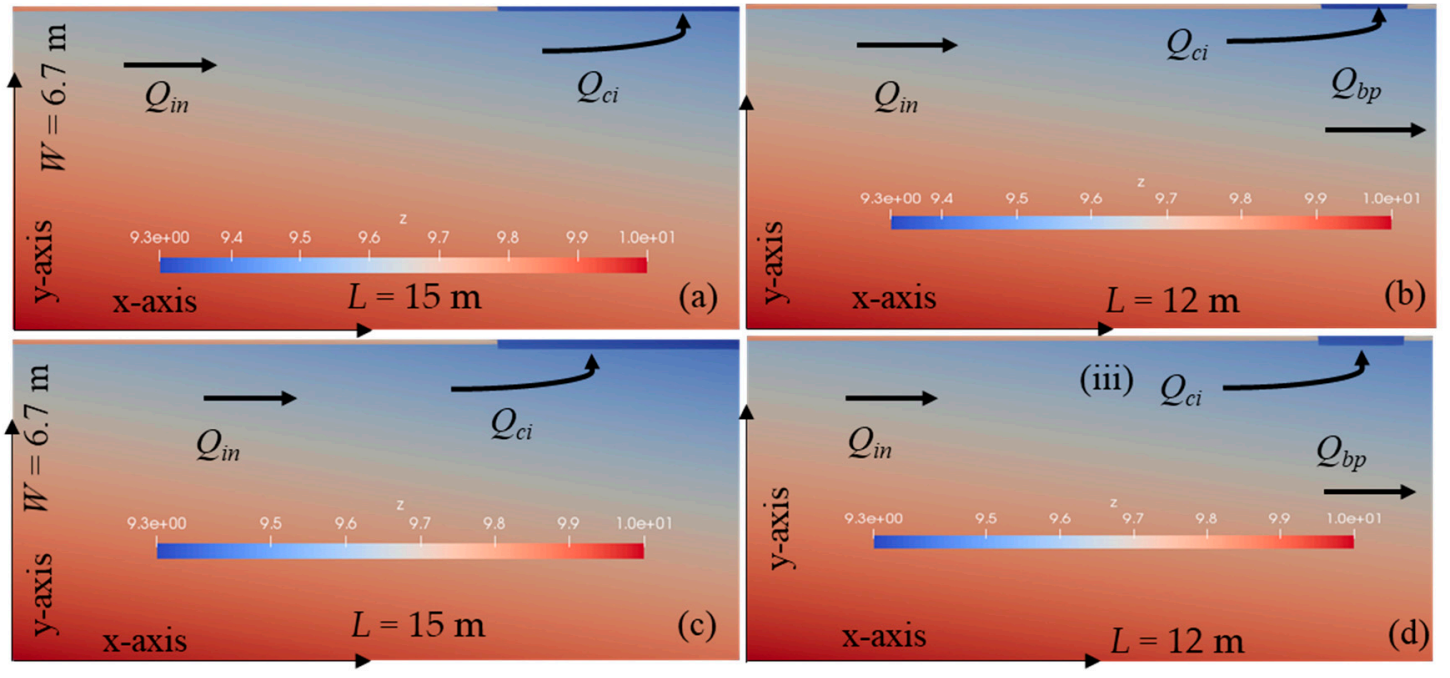

Figure 2. (a) DEM of a curb-cut case for determining $L_{T} ;$ (b) DEM of a curb-cut case for determining $E_{c i}$; (c) DEM of a road-curb cut case for determining $L_{T}$; (d) DEM of a road-curb cut case for determining $E_{c i}$. DEM of the curb inlet for the road is different for undepressed, curb-cut, and road-curb cut modeling cases while the rest part is the same. $Q_{i n}, Q_{c i}$, and $Q_{b p}$ are upstream inflow, intercepted flow, and bypassed flow of the curb inlet.

The digital elevation models (DEMs) for the two types of deep-cut curb inlets under different cross slopes and curb inlet lengths were established using MATLAB [21] code. Figure 2 shows examples of the plan view and high-resolution DEMs for four modeling cases with $S_{0}=0.01$ and $S_{x}=0.06$. Therefore, DEMs of the road surface shown in Figure 2a-d are the same for all four cases, and only DEMs for the inlet and associated cuts on the curb and adjacent road are different and discussed in more detail in Sections 2.2.1 and 2.2.2. Figure 2a,b is a modeling case for the curb-cut scenarios when the deep cut only occurs over the curb width $(0.10 \mathrm{~m})$. Figure $2 \mathrm{c}, \mathrm{d}$ is a modeling case for the road-curb cut scenarios when the deep cut occurs both over the curb $(0.10 \mathrm{~m})$ and a small part of road width (0.05 or $0.10 \mathrm{~m})$.

\subsubsection{Determining $100 \%$ Interception Curb Inlet Lengths}

Figure 2a shows the modeling case to determine $L_{T}$ for a cut depth $d=0.15 \mathrm{~m}$ over the curb inlet. The area in the simulation domain for all modeling cases in this study is $15 \mathrm{~m}$ in length ( $x$-direction) and $6.7 \mathrm{~m}$ in width ( $y$-direction) that includes $3 \mathrm{~m}$ of the car lane, $1.5 \mathrm{~m}$ of the bike lane, $2.1 \mathrm{~m}$ of the parking lane $(1.5 \mathrm{~m}+0.6 \mathrm{~m}$ gutter), and $0.1 \mathrm{~m}$ of the curb. When $y=0$, it is the centerline of the road; when $y=6.6-6.7 \mathrm{~m}$, it is the curb. The curb lasts $10 \mathrm{~m}$ in the $x$-direction and there is a long curb-inlet opening $(5 \mathrm{~m})$ at $x=10 \mathrm{~m}$ (Figure $2 \mathrm{a}, \mathrm{c})$ used to determine $L_{T}$ since the intercepted flow $\left(Q_{c i}\right)$ of a curb inlet is not affected by the downstream curb (i.e., $Q_{c i}=Q_{i n}$, bypass flow $Q_{b p}=0$ ).

The upstream inflow $Q_{i n}$ is set at the left boundary of the simulation domain and flows towards the downstream to the right boundary. The $100 \%$ interception curb inlet length $L_{T}$ is the flow length over the curb inlet determined by the numerical model simulation when $Q_{c i}$ is equal to $Q_{i n}$. The intercepted flow is the total flow left the simulation domain from the top boundary determined by the FullSWOF-ZG program. The bypass flow $Q_{b p}$ is the flow left the simulation domain from the downstream (right) boundary. In the model set up (Figure 2a,d), the curb opening length was $5 \mathrm{~m}$, longer than $L_{T}$ to be determined so that $Q_{b p}=0$.

All cell elevations in the simulation domain were calculated using a MATLAB program when the bottom-left-corner reference cell's elevation (the highest in the domain) was assumed to be $10 \mathrm{~m}$. The road surface elevations vary with longitudinal and cross slopes. All cells for the $0.1 \mathrm{~m}$ wide curb were set $0.2 \mathrm{~m}$ higher than the road surface cells. The cell's elevations inside the curb inlet were first calculated using the same cross slope of the road surface and then subtracted by the deep cut depth to 
obtain the final cell's elevation for the deep cut modeling cases. It was expected to help and allow the runoff to flow into the roadside bioretention. The deep cut inside the curb inlet has a local depression $d$ from the nearby road surface. It is simple and easy to implement when retrofitting curb inlets for the bioretention strip projects to hopefully improve the inlet efficiency.

Two hundred modeling cases were selected and modeled to determine $L_{T}$ for the combinations of $10 S_{x}, 10 Q_{\text {in }}$ (Table 1$)$, and two $d(0.10$ and $0.15 \mathrm{~m})$. The cell size of DEMs for all 200 cases was $0.025 \mathrm{~m}$ determined by a sensitivity analysis. The simulated water depth along the curb increases along the $x$-direction first and then starts to decrease after it reaches the curb inlet $(x>10 \mathrm{~m})$ [12]. The depth limit equal to $0.2 \mathrm{~mm}$ was used to determine $L_{T}$ and already tested and verified in the previous study [12].

Table 1. Sequence numbers and corresponding geometry and inflow parameters of curb inlet modeling cases.

\begin{tabular}{|c|c|c|c|c|c|c|c|}
\hline Sequence No. & $S_{x}(\%)$ & $\begin{array}{l}\text { Modeling Case } \\
\text { Index }\end{array}$ & $\begin{array}{l}\text { Modeling Case } \\
\text { Index }{ }^{2}\end{array}$ & $Q_{i n}(\mathrm{~L} / \mathrm{s})$ & $\begin{array}{c}\text { Modeling Case } \\
\text { Index }^{3}\end{array}$ & $\begin{array}{l}\text { Modeling Case } \\
\text { Index }\end{array}$ & $L_{c i}(\mathrm{~m})$ \\
\hline 1 & 1.5 & UDX1Q1 & D1X1Q1 & 6 & UDX1L1 & D1X1L1 & 0.15 \\
\hline 2 & 2.0 & UDX2Q2 & D1X2Q2 & 8 & UDX2L2 & D1X2L2 & 0.30 \\
\hline 3 & 2.5 & UDX3Q3 & D1X3Q3 & 10 & UDX3L3 & D1X3L3 & 0.45 \\
\hline 4 & 3.0 & UDX4Q4 & D1X4Q4 & 12 & UDX4L4 & D1X4L4 & 0.60 \\
\hline 5 & 3.5 & UDX5Q5 & D1X5Q5 & 14 & UDX5L5 & D1X5L5 & 0.75 \\
\hline 6 & 4.0 & UDX6Q6 & D1X6Q6 & 16 & UDX6L6 & D1X6L6 & 0.90 \\
\hline 7 & 4.5 & UDX7Q7 & D1X7Q7 & 18 & UDX7L7 & D1X7L7 & 1.05 \\
\hline 8 & 5.0 & UDX8Q8 & D1X8Q8 & 20 & UDX8L8 & D1X8L8 & 1.20 \\
\hline 9 & 5.5 & UDX9Q9 & D1X9Q9 & 22 & UDX9L9 & D1X9L9 & 1.35 \\
\hline 10 & 6.0 & UDX10Q10 & D1X10Q10 & 24 & UDX10L10 & D1X10L10 & 1.50 \\
\hline
\end{tabular}

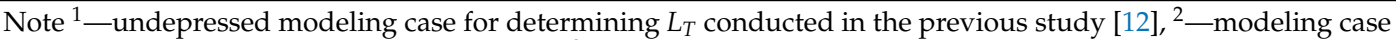
for determining $L_{T}$ when cut depth $d=0.1 \mathrm{~m},{ }^{3}$ - undepressed modeling cases for determining $E_{c i}$ of different $L_{c i}$ when $Q_{i n}=10 \mathrm{~L} / \mathrm{s}$ conducted in the previous study [12], ${ }^{4}$-modeling cases for determining $E_{c i}$ of different $L_{c i}$ when $Q_{\text {in }}=10 \mathrm{~L} / \mathrm{s}$ when $d=0.1 \mathrm{~m}$.

Commonly used $S_{0}$ and $S_{x}$ values in stormwater drainage design were chosen from the HEC-22 [3] for 100 modeling cases, which have one longitudinal slope $S_{0}=0.01(1 \%), 10$ cross slopes $S_{x}=0.015-0.06$ $(1.5-6 \%)$, and 10 upstream inflows $Q_{i n}=6-24 \mathrm{~L} / \mathrm{s}$ (Table 1). In this case study, the longitudinal slope of $1 \%$ was used. In China, many roads were constructed with small longitudinal slopes, and there are also many roads with steep longitudinal slopes over the world. How the deep cut can affect $L_{T}$ for the roads with other longitudinal slopes is not comprehensively studied here and should be done in a future study. As reported in Pavement and Geometric Design Criteria for Minimizing Hydroplaning, a cross slope of $2 \%$ has little effect on driver effort in steering or on friction demand for vehicle stability. The use of a cross slope steeper than $2 \%$ on pavements with a central crown line is not desirable [22]. In areas of intense rainfall, a somewhat steeper cross slope $(2.5 \%)$ may be used to facilitate drainage as HEC-22 [3] states.

The first 100 modeling cases have a cut depth $d$ of $0.10 \mathrm{~m}$ and the second 100 modeling cases having $d=0.15 \mathrm{~m}$. The case number was named using the sequence number (1-10) of the parameter's choice of $S_{x}$ and $Q_{i n}$. For example, the modeling case D1X1Q1 means the road having $S_{0}=0.01(1 \%)$, a cut depth $d=0.10 \mathrm{~m}, S_{x}=0.015(1.5 \%)$ with $Q_{i n}=6 \mathrm{~L} / \mathrm{s}$ for upstream inflow. The modeling case D2X1Q1 has a cut depth $d=0.15 \mathrm{~m}$ with the same $S_{0}, S_{x}$, and $Q_{i n}$ for the D1X1Q1 case.

\subsubsection{Evaluating the Curb Inlet Efficiency}

To evaluate the curb inlet efficiency at different inlet lengths (Figure 2b), the second 200 modeling cases were selected: 10 choices of $L_{c i}, 2$ cut depths $d(0.10$ and $0.15 \mathrm{~m})$, and the same 10 choices for $S_{x}$, which were used for the modeling cases to determine $L_{T}$. Ten curb inlet opening lengths $L_{c i}$ that range from 0.15 to $1.5 \mathrm{~m}$ with an increase of $0.15 \mathrm{~m}$ were adapted based on the curb inlet survey conducted by Stoolmiller et al. [23]. The imposed upstream inflow $Q_{i n}$ was chosen as $10 \mathrm{~L} / \mathrm{s}$ for the left boundary condition of the domain for the second 200 modeling cases. A part of the inflow is intercepted by the curb inlet, i.e., $Q_{c i}$, and the remainder of the inflow is discharged or bypassed downstream along 
the road, i.e., $Q_{b p}$ where the inlet length $L_{c i}$ is less than $L_{T}$ for $100 \%$ interception. The modeling case D1X1L1 means the road having $S_{0}=0.01(1 \%)$, cut depth $d=0.10 \mathrm{~m}, S_{x}=0.015(1.5 \%)$ with $L_{c i}=0.15 \mathrm{~m}$. Figure $2 \mathrm{~b}$ shows DEM and model set up for D1X10L10 $\left(d=0.1 \mathrm{~m}, L_{c i}=1.50 \mathrm{~m}\right)$. An undepressed curb inlet when $d=0$ has been simulated in a previous study [12].

\subsection{Modeling Cases for the Road-Curb Cut Curb Inlets}

\subsubsection{Determining $100 \%$ Interception Curb Inlet Lengths}

Figure 2c shows the plan view and high-resolution DEM for the modeling case with $S_{0}=0.01$ and $S_{x}=0.06$ for a road-curb cut scenario. The difference for two groups of the road-curb cut cases is the cut width $w$ on the road surface $\left(w=w_{2}-w_{1}\right.$ ) (Figure $1 \mathrm{~d}$ ): $0.05 \mathrm{~m}$ or $0.10 \mathrm{~m}$. The road cut width $w$ of Figure $2 \mathrm{c}$ is $0.10 \mathrm{~m}$ and the cut depth $d$ over the curb and adjacent road is $0.10 \mathrm{~m}$.

In this part of the case study, the cut depth for the curb inlet and road surface was fixed at $0.10 \mathrm{~m}$ for all cases with $S_{0}=0.01(1 \%)$. The case number was named using the sequence number (1-10) of the parameter's choice of $w, S_{x}$, and $Q_{i n}$. For example, the modeling case R1X1Q1 means the road having a cut width $w=0.05 \mathrm{~m}, S_{x}=0.015(1.5 \%)$, and $Q_{i n}=6 \mathrm{~L} / \mathrm{s}$ for upstream inflow. Ten R1XmQm $(\mathrm{m}=1,2$, $\ldots, 10)$ modeling cases and parameters are listed in Table 2 . The 100 modeling cases $R 2 X m Q n$ ( $m$ or $n$ $=1,2, \ldots, 10)$ mean the road has a cut width $w=0.10 \mathrm{~m}$. The curb opening length $(5 \mathrm{~m})$ was set large enough to intercept $100 \%$ inflow for these third 200 modeling cases.

Table 2. Sequence numbers and corresponding geometry and inflow parameters of road-curb cut inlet modeling cases

\begin{tabular}{cccccc}
\hline Sequence No. & $\boldsymbol{S}_{\boldsymbol{x}}(\mathbf{\%})$ & $\begin{array}{c}\text { Modeling } \\
\text { Case Index }\end{array}$ & $\boldsymbol{Q}_{\boldsymbol{i n}}(\mathbf{L} / \mathbf{s})$ & $\begin{array}{c}\text { Modeling } \\
\text { Case Index }\end{array}$ & $\boldsymbol{L}_{\boldsymbol{c} i}(\mathbf{m})$ \\
\hline 1 & 1.5 & R1X1Q1 & 6 & R1X1L1 & 0.15 \\
2 & 2.0 & R1X2Q2 & 8 & R1X2L2 & 0.30 \\
3 & 2.5 & R1X3Q3 & 10 & R1X3L3 & 0.45 \\
4 & 3.0 & R1X4Q4 & 12 & R1X4L4 & 0.60 \\
5 & 3.5 & R1X5Q5 & 14 & R1X5L5 & 0.75 \\
6 & 4.0 & R1X6Q6 & 16 & R1X6L6 & 0.90 \\
7 & 4.5 & R1X7Q7 & 18 & R1X7L7 & 1.05 \\
8 & 5.0 & R1X8Q8 & 20 & R1X8L8 & 1.20 \\
9 & 5.5 & R1X9Q9 & 22 & R1X9L9 & 1.35 \\
10 & 6.0 & R1X10Q10 & 24 & R1X10L10 & 1.50 \\
\hline
\end{tabular}

Note ${ }^{1}$-modeling case for determining $L_{T}$ with cut depth $d=0.10 \mathrm{~m},{ }^{2}$-modeling cases for determining $E_{c i}$ of different lengths $L_{c i}$ when $Q_{i n}=10 \mathrm{~L} / \mathrm{s}$.

\subsubsection{Evaluating the Curb Inlet Efficiency}

To evaluate the curb inlet efficiency at different inlet lengths (Figure 2d) with different cut widths over the road and curb inlet, the fourth 200 modeling cases were selected using 10 choices of $L_{c i}, 2$ cut widths $w(0.05$ and $0.1 \mathrm{~m})$, and the same 10 choices for $S_{x}$, which were used for the third 200 modeling cases to determine $L_{T}$. Ten curb inlet lengths $L_{c i}$ were again ranged from $0.15-1.5 \mathrm{~m}$ with an increase of $0.15 \mathrm{~m}$ [23]. The imposed upstream inflow $Q_{i n}$ was chosen as $10 \mathrm{~L} / \mathrm{s}$ for the left boundary condition of the domain. The modeling case R1X1L1 means the road has a cut width $w=0.05 \mathrm{~m}, S_{x}=0.015(1.5 \%)$, and $L_{c i}=0.15 \mathrm{~m}$ (Table 2).

\section{Results and Discussion}

\subsection{0\% Interception Curb Inlet Length for the Curb-Cut and Road-Curb Cut Scenarios}

Figure 3 shows the comparison of $100 \%$ interception curb inlet length for 100 undepressed cases, 200 curb-cut modeling cases with $d=0.10 \mathrm{~m}$ and $0.15 \mathrm{~m}$. The $L_{T}$ for 100 undepressed cases ranges from $1.91 \mathrm{~m}$ to $7.59 \mathrm{~m}$ with an average \pm standard deviation equal to $3.69 \pm 1.24 \mathrm{~m}$. The percentage 
changes of $L_{T}$ between the curb-cut cases (D1 and D2) and the undepressed cases (UD) with the same $S_{0}, S_{x}$, and $Q_{i n}$ range from $-1.09 \%$ to $0.00 \%$ with the mean percentage change equal to $-0.25 \%$. The standard deviation of the percentage changes between the undepressed cases and the curb-cut cases was equal to $0.33 \%$. The $100 \%$ interception curb-inlet lengths for the 200 curb-cut cases with different cut depths were quite similar to the $L_{T}$ for corresponding undepressed cases with the same cross slope and upstream inflow. It means if the deep cut is only made over the curb inlet width, the cut depth $(d=0,0.05$, and $0.10 \mathrm{~m})$ does not make much difference in $L_{T}$ for $S_{x}=1.5-6 \%$.

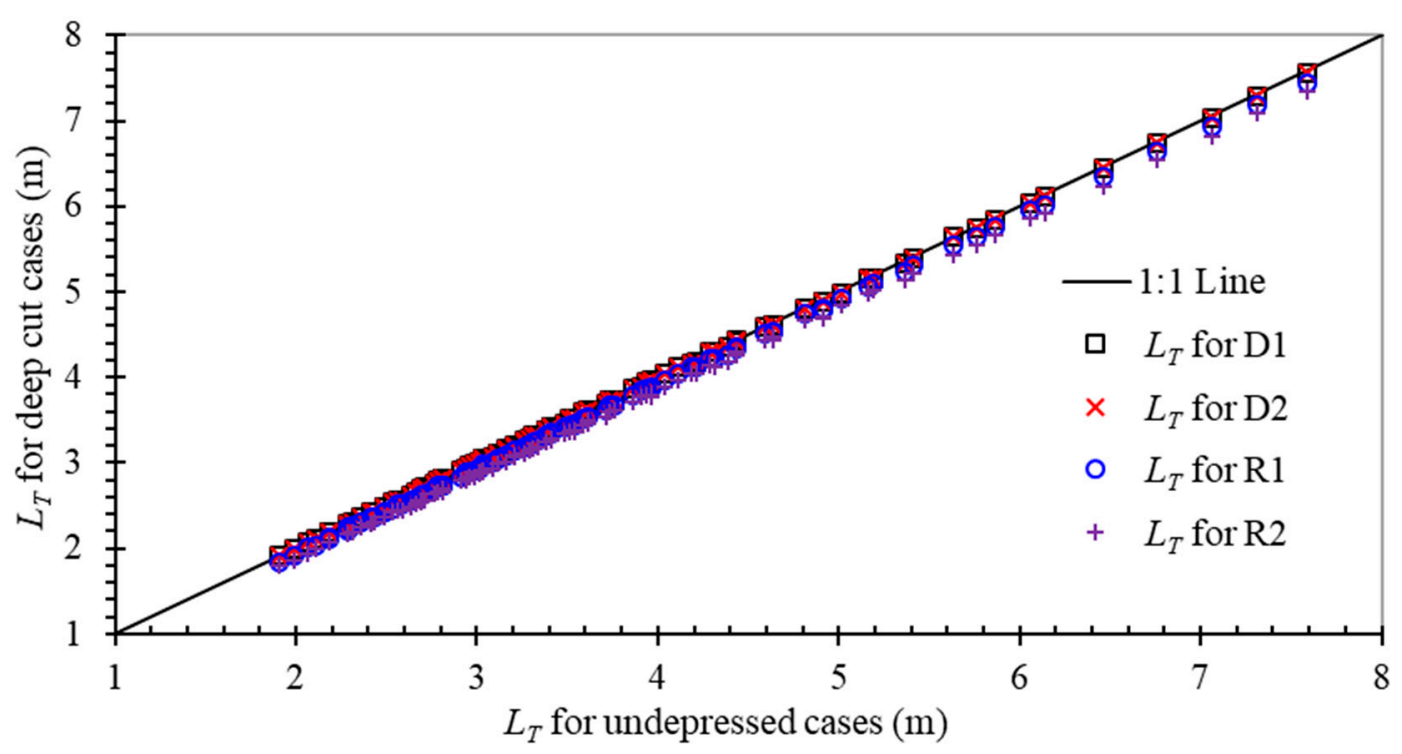

Figure 3. Comparison of $L_{T}$ between curb-cut inlet cases, road-curb cut inlet cases, and undepressed curb inlet cases.

Figure 3 also shows the comparison of $100 \%$ interception curb inlet lengths for the undepressed inlets and the road-curb cut inlets with $w=0.05 \mathrm{~m}$ and $0.10 \mathrm{~m}$ from 100 modeling cases by varying $S_{x}$ and $Q_{i n}$. The percentage changes of $L_{T}$ between the R1 road-curb cut cases with $w=0.05 \mathrm{~m}$ and the undepressed cases range from $-3.92 \%$ to $-1.47 \%$ with the mean change and its standard deviation of $-2.31 \%$ and $0.48 \%$. The percentage changes of $L_{T}$ between the $\mathrm{R} 2$ road-curb cut cases with $w=0.1 \mathrm{~m}$ and the undepressed cases range from $-6.54 \%$ to $-3.08 \%$ with the mean change and its standard deviation of $-4.45 \%$ and $0.78 \%$. The $100 \%$ interception curb inlet length sequence from the largest to smallest was UD > R1 > R2. The maximum reduction of $L_{T}$ for R1 and R2 cases in comparison to corresponding UD cases is 0.15 and $0.25 \mathrm{~m}$, respectively.

\subsection{Curb inlet Efficiency for the Curb-Cut Scenarios}

Figure 4 shows the comparison of simulated curb inlet efficiencies for 100 undepressed modeling cases, 200 curb-cut modeling cases with $d=0.10 \mathrm{~m}$ and $0.15 \mathrm{~m}$. The inlet efficiencies for the undepressed curbs range from $4.68 \%$ to $94.47 \%$ with an average \pm standard deviation equal to $43.68 \% \pm 25.04 \%$ when $L_{c i}$ varied from 0.15 to $1.5 \mathrm{~m}$. The inlet efficiencies for the D1 and D2 curbs range from $5.67 \%$ to $94.85 \%$ with an average \pm standard deviation equal to $46.06 \% \pm 24.62 \%$. Simulated curb inlet efficiencies are the same for $d=0.1 \mathrm{~m}$ and $0.15 \mathrm{~m}$ when other parameters $\left(S_{0}, S_{x}\right.$, and $\left.L_{c i}\right)$ are the same. The percent changes of the curb inlet efficiencies between the curb-cut cases (D1 and D2) and the undepressed cases (UD) range from $0.41 \%$ to $26.92 \%$ with the mean percentage change of $8.91 \%$ and the standard deviation of $6.87 \%$. Figure 4 shows a slight difference between the undepressed and curb-cut cases when $E_{c i}$ between 0.2 and 0.6. The $E_{c i}$ changes between the curb-cut cases (D1 and D2) and the undepressed cases (UD) range from $0.39 \%$ to $6.01 \%$ and are greater than zero so that the curb-cut inlets only increase $E_{c i}$ a few percent. 


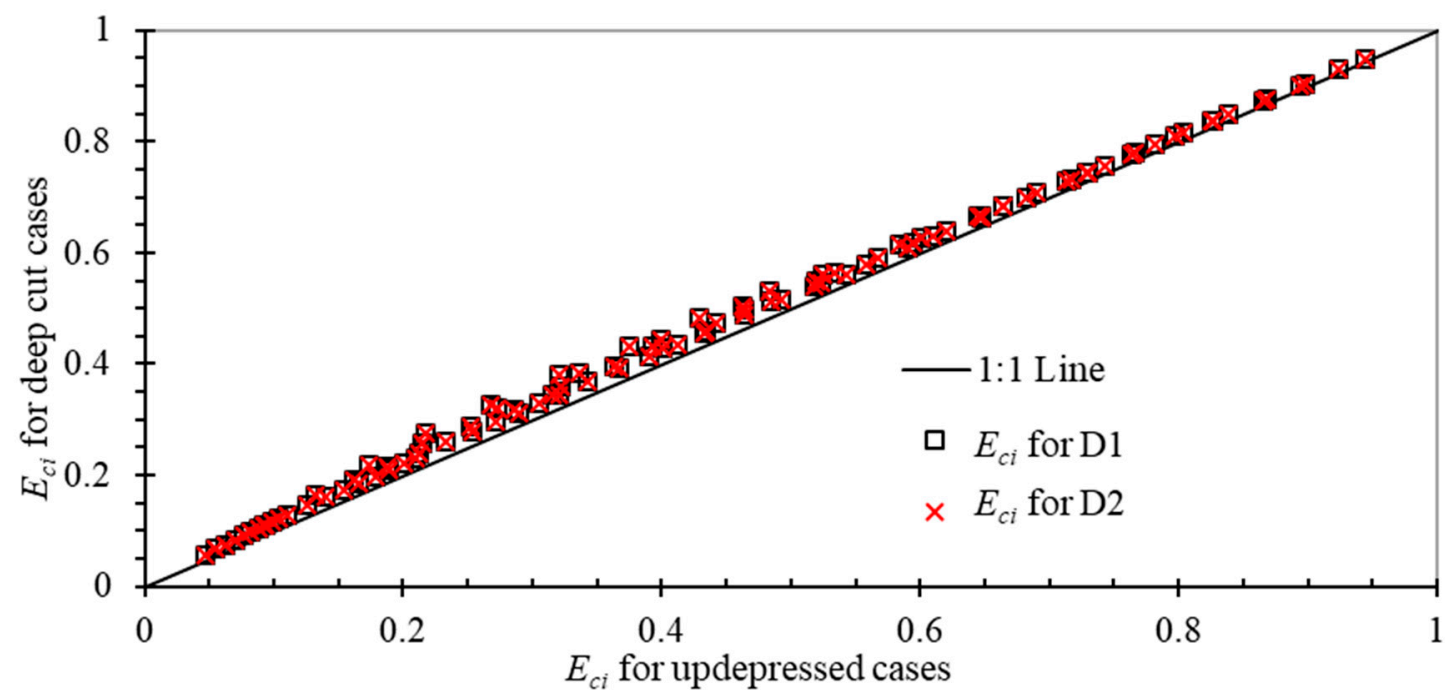

Figure 4. Comparison of $E_{c i}$ between curb-cut inlet cases (D1 and D2) and undepressed curb inlet cases.

Figures 3 and 4 show that the differences in modeling cases between the curb-cut and undepressed curb inlets are very small in terms of the $100 \%$ interception curb inlet length and the inlet efficiency. Therefore, it is not an efficient method to improve the curb inlet efficiency only by cutting the curb inlet because $E_{c i}$ only increases by $0.39-6.01 \%$. The change of cut depth from 0.10 to $0.15 \mathrm{~m}$ has almost no influence on the $100 \%$ interception curb inlet length and the curb inlet efficiency based on the simulation results.

\subsection{Curb inlet Efficiencies Evaluation for the Road-Curb Cut Scenarios}

Figure 5a shows the comparison of curb inlet efficiency for undepressed (UD) cases, road-curb cut cases with $w=0.05 \mathrm{~m}$ (R1 cases) and $0.10 \mathrm{~m}$ (R2 cases). The change of curb inlet efficiency between the $\mathrm{R} 1$ road-curb cut cases and undepressed cases ranges from $2.79 \%$ to $14.16 \%$ with the average \pm standard deviation equal to $8.21 \pm 2.55 \%$. The percentage changes of curb inlet efficiency between the $\mathrm{R} 2$ road-curb cut cases and undepressed cases range from $4.29 \%$ to $27.88 \%$ with the average \pm standard deviation equal to $15.63 \pm 5.16 \%$.
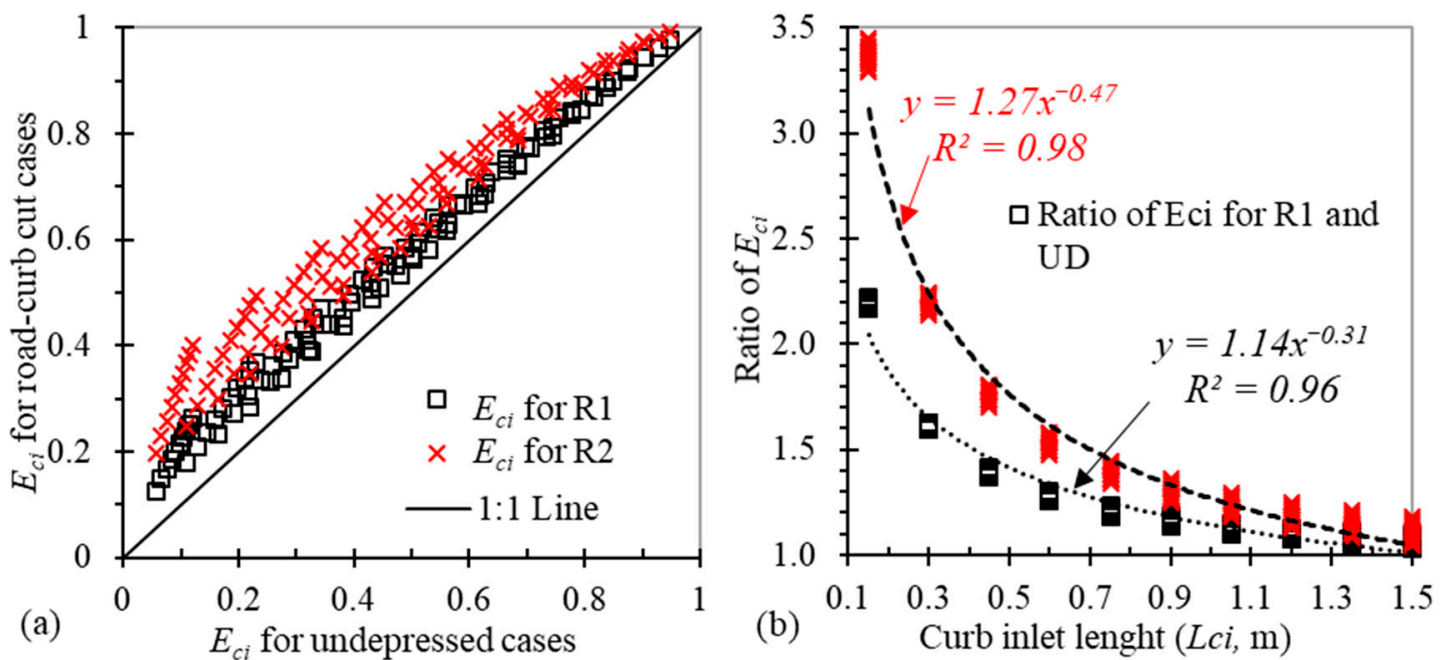

Figure 5. (a) Comparison of $E_{c i}$ between the road-curb cut inlet cases and undepressed inlets with $Q_{i n}=10 \mathrm{~L} / \mathrm{s},(\mathbf{b})$ ratio of $E_{c i}$ for R1 and R2 cases versus $L_{c i}$. 
Figure $5 \mathrm{~b}$ plots the ratio of curb inlet efficiency between the road-curb cut cases and corresponding undepressed cases versus the curb inlet length. It is clearly shown that the curb inlet efficiency was largely improved for small curb inlet length. For bioretention facilities in Sponge City projects, many curb inlets have short opening lengths. When $L_{c i}$ is $0.15 \mathrm{~m}$ and $0.3 \mathrm{~m}$, the curb inlet efficiency is average 2.19 and 3.37 times of $E_{c i}$ for undepressed inlets, respectively, when $Q_{i n}=10 \mathrm{~L} / \mathrm{s}$. The road cut width $w$ increases from $0.05 \mathrm{~m}$ (R1) to $0.10 \mathrm{~m}(\mathrm{R} 2), E_{c i}$ for R2 is 1.0-1.55 times of $E_{c i}$ for R1. Figure 6 shows the curb inlet efficiency $E_{c i}$ for the undepressed cases, the road-curb cut cases with $w=0.05 \mathrm{~m}$ and $0.10 \mathrm{~m}$ versus the ratio of $L_{c i} / L_{T}$. The dark line in Figure 6 shows the calculated efficiencies using the equation developed in a previous study [12].

$$
E_{c i}=1-\left[1-\left(\frac{L_{c i}}{L_{T}}\right)\right]^{2.42}
$$

where $E_{c i}$ is the curb inlet efficiency with different curb inlet length, $L_{c i}$ is the curb inlet length, and $L_{T}$ is the $100 \%$ interception curb inlet length.

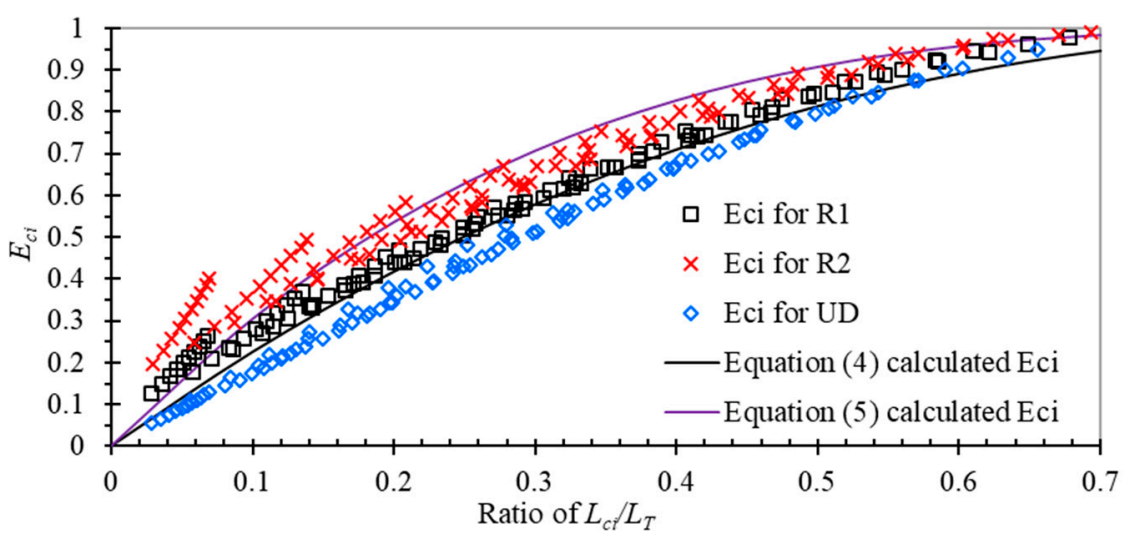

Figure 6. $E_{c i}$ for undepressed (UD) and the road-curb cut inlet cases versus the ratio of $L_{c i} / L_{T}$.

A new regression equation of $E_{c i}$ to $L_{c i} / L_{T}$ for R2 cases was developed with an RMSE of $6.26 \%$ for these simulation cases.

$$
E_{c i}=1-\left[1-\left(\frac{L_{c i}}{L_{T}}\right)\right]^{3.44}
$$

Equation (5) was developed only based on those 100 cases with a longitudinal slope equal to $1 \%$. A general equation that can be used to calculate the road-curb cut inlet efficiency with a wide range of parameters for the road surface $\left(S_{0}, S_{x}\right.$, and $\left.Q_{i n}\right)$, curb inlet $\left(L_{c i}\right)$, and cut width $(w)$ still needs to be determined based on more simulation cases in a future study.

For Equation (4), the root mean square error (RMSE) between fitted and simulated $E_{c i}$ is $3.93 \%$. The differences of curb inlet efficiency between the calculated and simulated results for undepressed cases (UD) range from $-2.43 \%$ to $7.43 \%$ with the average \pm standard deviation equal to $4.06 \pm 2.34 \%$. The calculated $E_{c i}$ is therefore on the average $4.06 \%$ larger than the simulated $E_{c i}$ (Figure 6). Its RMSE is $4.68 \%$, just slightly larger than the RMSE of Equation (5). It shows the calculated results with Equation (5) match reasonably well with the undepressed cases.

The differences of curb inlet efficiency between the calculated and simulated results for the R1 road-curb cut cases range from $-10.70 \%$ to $0.35 \%$ with the average \pm standard deviation equal to $-3.25 \pm 2.28 \%$, which is within the RMSE of Equation (4). The percentage change of curb inlet efficiency between the calculated and simulated results for the R2 road-curb cut cases ranges from $-24.07 \%$ to $-4.86 \%$ with the average \pm standard deviation equal to $-9.79 \pm 4.50 \%$. Therefore, Equation (4) underestimated the curb inlet efficiencies for the road-curb cut cases with $w=0.01 \mathrm{~m}$, and the average difference is more than twice the RMSE of Equation (4). 


\section{Conclusions}

Two kinds of retrofit scenarios for curb inlets were simulated using the FullSWOF_ZG program in this case study: (1) The deep cut is made only over the width $(0.01 \mathrm{~m})$ of the curb inlet (D1 and D2 cases); (2) both the curb inlet and a small part of the road surface have a deep cut (R1 and R2 cases). Simulated results of 800 modeling cases were compared with undepressed curb inlet results to explore and quantify the efficiency improvement of the deep-cut curb inlets. The percentage changes of $L_{T}$ between the curb-cut cases and the undepressed cases (UD) with the same $S_{0}, S_{x}$, and $Q_{\text {in }}$ range from $-1.09 \%$ to $0.00 \%$ with the mean percentage change equal to $-0.25 \%$. The $L_{T}$ for curb-cut cases with different cut depths were quite similar to the $L_{T}$ for corresponding undepressed cases with the same cross slope and upstream inflow. It means if the deep cut is only made over the curb inlet width, the cut depth $(d=0,0.05$, and $0.10 \mathrm{~m})$ does not make much difference in $L_{T}$ for $S_{x}=1.5-6 \%$ tested in this study. The $E_{c i}$ changes between the curb-cut cases and the undepressed cases (UD) range from $0.4 \%$ to $6.0 \%$ and are greater than zero so that the curb-cut only increases $E_{c i}$ a few percent. Therefore, it is not an efficient method to improve the curb inlet efficiency only by cutting the curb inlet because $E_{c i}$ only increases up to $6.0 \%$.

The sequence from the largest to smallest for $100 \%$ interception curb inlet length $L_{T}$ was UD > R1 $>\mathrm{R} 2$ cases. The maximum reduction of $L_{T}$ for $\mathrm{R} 1$ and $\mathrm{R} 2$ cases in comparison to corresponding UD cases is 0.15 and $0.25 \mathrm{~m}$, respectively. The increases of curb inlet efficiency between the road-curb cut cases R1 or R2 and the undepressed cases range from $2.79 \%$ to $14.2 \%$ and $4.3 \%$ to $27.9 \%$, respectively. The road-curb cut cases improve the curb inlet efficiency to a large extent so that they can be used in the SPC retrofit projects or other urban drainage projects to reduce flooding potentials. This case study used limited combinations of longitudinal slope (1\%), 10 cross slopes, 10 upstream inflows, and 10 inlet lengths to derive the above results. Even the relation of $E_{c i}$ and $L_{c i} / L_{T}$ was explored (Equation (5)), however, a general equation used to design and evaluate the road-curb cut inlets should be developed based on more simulation cases with a wide range of input parameters in a future study.

Author Contributions: X.L. developed the program, conducted the simulations, analyzed the result, and prepared the manuscript draft. X.F. supervised model development, simulation runs, data analysis, and revised the manuscript. C.W., G.C., Q.W., Z.H., J.W. and S.W. supervised the writing, data analysis, and revised the manuscript. All authors have read and agreed to the published version of the manuscript.

Funding: This research has been financially supported by the National Key Research and Development Program of China (2018YFC1508200), the Fundamental Research Funds for the Central Universities (B200202029 and B200202030), and Project 41901020 supported by NSFC.

Conflicts of Interest: The authors declare no conflict of interest.

Data availability: Some or all data, models, or code generated or used during the study are proprietary or confidential and may only be provided with restrictions. The model input and output data are specifically designed for a research numerical model. They are available upon request but are not useful for the general public.

\section{References}

1. Izzard, C.F. Tentative results on capacity of curb opening inlets. In Proceedings of the 29th Annual Conference of the Highway Research Board, Washington, DC, USA, 13-16 December 1950; Highway Research Board: Washington, DC, USA, 1950; pp. 11-13.

2. Li, W.H. Hydraulic theory for design of stormwater inlets. In Proceedings of the 33rd Annual Meeting of the Highway Research Board, Washington, DC, USA, 12-15 January 1954; Highway Research Board: Washington, DC, USA, 1954; pp. 83-91.

3. Brown, S.; Stein, S.; Warner, J. Urban Drainage Design Manual: Hydraulic Engineering Circular No. 22 (FHWA-NHI-10-009, HEC-22); National Highway Institute: Arlington, VA, USA, 2009.

4. Hammonds, M.A.; Holley, E. Hydraulic Characteristics of Flush Depressed Curb Inlets and Bridge Deck Drains (FHWA/TX-96/1409-1); Texas Department of Transportation: Austin, TX, USA, 1995. 
5. Uyumaz, A. Urban drainage with curb-opening inlets. In Proceedings of the Ninth International Conference on Urban Drainage (9ICUD), Portland, OR, USA, 8-13 September 2002; American Society of Civil Engineers: Portland, OR, USA, 2002; pp. 1-9.

6. Guo, J.C.Y.; MacKenzie, K. Hydraulic Efficiency of Grate and Curb-Opening Inlets under Clogging Effect (CDOT-2012-3); Colorado Department of Transportation, DTD Applied Research and Innovation Branch: Denver, CO, USA, 2012.

7. Schalla, F.E.; Ashraf, M.; Barrett, M.E.; Hodges, B.R. Limitations of traditional capacity equations for long curb inlets. Transp. Res. Rec. J. Transp. Res. Board 2017, 2638, 97-103. [CrossRef]

8. Fang, X.; Jiang, S.; Alam, S.R. Numerical Simulations of Efficiency of Curb-Opening Inlets. J. Hydraul. Eng. 2009, 136, 62-66. [CrossRef]

9. Delestre, O.; Darboux, F.; James, F.; Lucas, C.; Laguerre, C.; Cordier, S. FullSWOF: A free software package for the simulation of shallow water flows. arXiv 2014, arXiv:1401.4125.

10. Gourbesville, P.; Cunge, J.; Caignaert, G. Advances in Hydroinformatics-SIMHYDRO 2014, 1st ed.; Springer: Singapore, 2014; p. 624.

11. Leandro, J.; Martins, R. A methodology for linking 2D overland flow models with the sewer network model SWMM 5.1 based on dynamic link libraries. Water Sci. Technol. 2016, 73, 3017-3026. [CrossRef] [PubMed]

12. Li, X.; Fang, X.; Chen, G.; Gong, Y.; Wang, J.; Li, J. Evaluating curb inlet efficiency for urban drainage and road bioretention facilities. Water 2019, 11, 851. [CrossRef]

13. Li, X.; Fang, X.; Gong, Y.; Li, J.; Wang, J.; Chen, G.; Li, M.H. Evaluating the road-bioretention strip system from a hydraulic perspective-Case studies. Water 2018, 10, 1778. [CrossRef]

14. Li, X.; Fang, X.; Li, J.; KC, M.; Gong, Y.; Chen, G. Estimating time of concentration for overland flow on pervious surfaces by particle tracking method. Water 2018, 10, 379. [CrossRef]

15. Unterweger, K.; Wittmann, R.; Neumann, P.; Weinzierl, T.; Bungartz, H.J. Integration of FullSWOF2D and PeanoClaw: Adaptivity and local time-stepping for complex overland flows. In Recent Trends in Computational Engineering-CE2014; Springer: Berlin/Heidelberg, Germany, 2015; pp. 181-195.

16. Cordier, S.; Coullon, H.; Delestre, O.; Laguerre, C.; Le, M.H.; Pierre, D.; Sadaka, G. FullSWOF Paral: Comparison of two parallelization strategies (MPI and SKELGIS) on a software designed for hydrology applications. In ESAIM: Proceedings; EDP Sciences: Julius, France, 2013; pp. 59-79.

17. Esteves, M.; Faucher, X.; Galle, S.; Vauclin, M. Overland flow and infiltration modelling for small plots during unsteady rain: Numerical results versus observed values. J. Hydrol. 2000, 228, 265-282. [CrossRef]

18. Spaliviero, F.; May, R.; Escarameia, M. Spacing of Road Gullies: Hydraulic Performance of BS EN 124 Gully Gratings and Kerb Inlets; Highways Agency, HR Wallingford Ltd.: Wallingford, UK, 2000; pp. 99-107.

19. Li, X.; Fang, X.; Wang, J.; Chen, G.; Li, J. Curb Inlet Efficiency Evaluation under Constant Rainfall and Upstream Inflow. In World Environmental and Water Resources Congress 2019: Water, Wastewater, and Stormwater; Urban Water Resources; and Municipal Water Infrastructure; American Society of Civil Engineers: Reston, VA, USA, 2019; pp. 20-33.

20. Nash, J.; Sutcliffe, J.V. River flow forecasting through conceptual models part I-A discussion of principles. J. Hydrol. 1970, 10, 282-290. [CrossRef]

21. MathWorks. MATLAB and Statistics Toolbox Release 2017a; The MathWorks Inc.: Natick, MA, USA, 2017.

22. Gallaway, B.M.; Ivey, D.L.; Hayes, G.; Ledbetter, W.B.; Olson, R.M.; Woods, D.L.; Schiller, R.F., Jr. Pavement and Geometric Design Criteria for Minimizing Hydroplaning FHWA-RD-79-31; Federal Highway Administration, Offices of Research and Development: Washington, DC, USA, 1979.

23. Stoolmiller, S.; Ebrahimian, A.; Wadzuk, B.M.; White, S. Improving the design of curb openings in green stormwater infrastructure. In Proceedings of the International Low Impact Development Conference, Nashville, Tennessee, 12-15 August 2018; pp. 168-176.

Publisher's Note: MDPI stays neutral with regard to jurisdictional claims in published maps and institutional affiliations. 